\title{
Alcances poéticos y culturales de una tipología mítica ovidiana
}

Eleonora Tola

CONICET-Universidad Nacional de Córdoba, Argentina

elytola@gmail.com

\section{Resumen:}

A partir de un enfoque "diferencial" del mito, abordamos la versión ovidiana del Ciclo tebano en el libro III de las Metamorfosis. La identificación de algunas valencias poéticas e ideológicas propias de esta actualización de la saga mítica nos permite explicitar el funcionamiento literario de uno de los principales motivos culturales del sistema romano de creencias. Mostramos que la leyenda fundacional de Cadmo construye de manera emblemática un patrón que atraviesa las representaciones de la historia colectiva en la literatura latina.

Palabras Clave: Ovidio, Mito, Ciclo de Tebas, Roma.

\section{ABSTRACT:}

From a "differential" approach to myth, I study the Theban Cycle in Book III of Ovid's Metamorphoses. The underlining of some poetic and ideological issues in the rewriting of that legendary story allows me to explain the literary functioning of a major cultural topic in Rome. Moreover, I show that Cadmus's foundational legend shapes a specific pattern that mostly conveys the representations of the collective history within Latin literature.

KeYwords: Ovid, Myth, Theban Cycle, Rome.

Desde sus comienzos, la literatura latina codificó una suerte de grilla mítica que fue explotada principalmente por el género trágico, como lo demuestra el recorte de ciclos legendarios en los textos republicanos $\operatorname{conservados}^{1}$. Si la producción ciceroniana confirma dicha dinámica con la inclusión paradigmática de algunos temas mítico-trágicos ${ }^{2}$, las Metamorfosis de Ovidio tienen, sin lugar a dudas, un estatus privilegiado en el sistema literario romano. Las tipologías míticas del carmen perpetuum orientaron, incluso, el desarrollo de la epopeya y de la tragedia de época imperial, dado que los motivos míticos de estas últimas remiten a modelos griegos ya reelaborados por el poema ovidiano ${ }^{3}$. Según mostró P. Esposito ${ }^{4}$, la leyenda tebana es particularmente significativa al respecto, en virtud de su potencial analógico. Los crímenes cometidos dentro de un linaje mitológico permitían referir, pues, a los conflictos intestinos de fines de la República, cuya relectura se instaló con especial interés en los períodos neroniano y flavio. De hecho, ese capítulo de la historia de Roma forjó, desde los tiempos de Cicerón, un imaginario cultural persistente que los poetas integraron, de variadas formas, a sus respectivos códigos genéricos. Como es sabido, una extensa sección de las Metamorfosis ovidianas está consagrada al ciclo tebano, que ocupa la totalidad del libro tercero y culmina en el cuarto con las transformaciones de Cadmo y Harmonía (IV, 563-603). Por cierto, en el período augustal ese corpus de leyendas ya contaba con una tradición literaria conocida ${ }^{5}$. No obstante, más allá de esos modelos, la especificidad del relato ovidiano de Cadmo y su dinastía radica en la focalización de un módulo temático y narrativo cuyo eje es el entrecruzamiento de una mirada, una transgresión y una metamorfosis-castigo de los personajes ${ }^{6}$. Dicho módulo inscribe la trama primaria de los mitos ${ }^{7}$ en la poética del texto, pero, más aún, permite entrelazar los episodios del ciclo con vistas a orientar su interpretación ${ }^{8}$. Por medio de una arquitectura textual sustentada en la paradoja estilística, el episodio de Cadmo construye una red simbólica que produce sentido dentro del carmen ovidiano y, también, fuera de él.

A partir de sus orígenes en el ámbito de la filosofía estoica con una función principalmente argumentativa (Cic., Parad. 3-4 ${ }^{9}$, la paradoja fue apropiada por la retórica clásica que, en una primera instancia, la 
introdujo en el dominio forense respecto del tratamiento de las llamadas "causas admirables" y "opuestas al sentido común” (Quint., IV, 1, 40-41) ${ }^{10}$; posteriormente, el recurso quedó incorporado como una figura de dicción y de pensamiento basada en la afirmación de dos cosas contradictorias tendiente a provocar un efecto de sorpresa que indicaba una nueva etapa del discurso ${ }^{11}$. Estrechamente asociada con la irrupción de un hecho inesperado - percibido incluso como una 'anomalía'-, la paradoja actúa entonces simultáneamente sobre el pensamiento y las palabras. Así entendida, se trata de un recurso con amplios alcances lingüísticos y conceptuales, los cuales operan en diversos niveles de los textos y adquieren sentido en el marco de cada proyecto estético. Desde esta perspectiva, las inversiones y consecuentes ambivalencias que atraviesan el relato programático del libro III de las Metamorfosis exceden, como veremos, el poema ovidiano y devienen funcionales a la concepción tradicional de la historia de Roma a lo largo de la literatura latina. Más exactamente, a través de dicho recurso el ciclo tebano de Ovidio se instaura como una matriz de lectura clave en la representación literaria de ciertos motivos culturales que definieron el sistema de creencias de la sociedad romana. A la luz de tales presupuestos, mostraremos que las actualizaciones de la paradoja en el relato mítico ovidiano trascienden sus alcances meramente retóricos o su uso dialéctico al servicio de la expresión de una verdad filosófica, sobre todo estoica. Por el contrario, mediante ese recurso la leyenda fundacional de Cadmo no solo deviene un aspecto central de la poética ovidiana de la transformación ${ }^{12}$, sino que instaura, al darle una forma explícita, un patrón conceptual que atraviesa las representaciones de la historia colectiva en la literatura latina ${ }^{13}$.

\section{Proceso metamórfico y ambivalencias textuales}

De un modo general, la crítica ha subrayado la relevancia estilística y narrativa de la paradoja en el carmen perpetuum ovidiano ${ }^{14}$. Al desdibujar los límites semánticos entre los conceptos, dicho recurso se adapta particularmente a la ambigüedad del proceso metamórfico, dado que este implica, como es sabido, un estado intermedio e indefinido en los personajes que padecen una transformación ${ }^{15}$. A. Zissos y I. Gildenhard ${ }^{16}$ consideran, incluso, que el estado original de caos, con cuya descripción se abre el poema (I, 18 -20), puede ser leído como el "Ur-paradox" del texto, puesto que esta imagen inicial aglutina una serie de elementos e imágenes contradictorios entre sí (non bene iunctarum discordia semina rerum "elementos discordes de cosas no bien ensambladas" I, 9; quia corpore in uno/ frigida pugnabant calidis, umentia siccis, / mollia cum duris, sine pondere, habentia pondus. "puesto que en un único cuerpo el frío luchaba con el calor, la humedad con lo seco, las cosas blandas con las duras, las que tenían peso con las que carecían de él” I, 18-20).

El libro III de las Metamorfosis expone de manera paradigmática este mecanismo estilístico-conceptual en el marco de una secuencia narrativa dedicada a un solo ciclo mítico ${ }^{17}$. Cadmo es presentado como un fundador en el comienzo mismo del relato (moenia fac condas Boeotiaque illa uocato" III, 13) ${ }^{18}$. Su transgresión de los nemora sacra anuncia no solo su propio destino (serpentem spectas? et tu spectabere serpens" III, 98), sino también las desgracias de su descendencia, dado que él es el primer eslabón de una dinastía y, al mismo tiempo, el incipit narrativo del libro. Sus nietos Acteón y Penteo y su hija Sémele confirman el estatus del personaje ${ }^{19}$. Si el primero se lanza también a un espacio prohibido y sorprende a la diosa Diana durante su baño(is fuit in uultu uisae sine ueste Dianae III, 185), el segundo ignora, por su parte, las advertencias de Tiresias ("quam felix esses.../ ne Bacchica sacra uideres. III, 517-518) y, convertido en espectador de los ritos prohibidos de las Bacantes, es desmembrado por su madre y sus tías presas del delirio dionisíaco (bic oculis illum cernentem sacra profanis III, 710). A su vez, Sémele es objeto de la venganza de Juno y muere al querer contemplar la naturaleza divina de Júpiter durante la unión amorosa (' qualem Saturnia' dixit / 'te solet amplecti, Veneris cum foedus initis/ da mibi te talem'. III, 293-295) ${ }^{20}$. Si bien los episodios de Tiresias $^{21}$ y Narciso interrumpen la linealidad de la historia del linaje de Cadmo, los motivos 
dominantes en la actualización mítica de Ovidio se multiplican, no obstante, a través de una serie de relaciones temáticas. Por un lado, las transformaciones sucesivas de Tiresias — hombre / mujer (324-327); mujer / hombre (330-331); hombre / profeta ciego (335-340) — reúnen y condensan las calamidades que pesan sobre la ciudad, a saber, la lucha contra la naturaleza (escena de las serpientes), un saber peligroso (acerca del goce sexual), la confrontación con los dioses (debate Júpiter / Juno) y la alteración de los límites físicos y culturales (metamorfosis sexuales); por otro lado, la mirada de Narciso desplaza la falta hacia el ámbito de los vínculos eróticos (quid uideat, nescit, sed quod uidet, uritur illo/ atque oculos idem qui decipit incitat error. III, 430-431; et placet et uideo, sed quod uideoque placetque/ non tamen inuenio III, 446-447). Este personaje que parece ser ajeno a las tragedias de Tebas se encuentra, sin embargo, estrechamente relacionado con ellas a partir de ciertas alusiones implícitas a Edipo, el hijo de un bisnieto de Cadmo ${ }^{22}$.

El itinerario narrativo de los descendientes directos del fundador de Tebas (Acteón, Sémele y Penteo) culmina en una inversión trágica de sus respectivas faltas o errores. Más exactamente, las metamorfosis que desencadenan sus conductas involucran algunos trastrocamientos paradójicos: si Cadmo deviene el objeto mismo de su sacrilegio (IV, 570-603), Acteón transformado en ciervo se instaura como un emblema del cazador-cazado (III, 200-252). Penteo, a su vez, encarna una inversión del oxímoron de Tiresias (meque sub his tenebris nimium uidisse quereris' III, 525) ${ }^{23}$ : capaz de ver, es no obstante presa de otro tipo de ceguera, de un estado de furor que arrastra al contemptor superum (III, 514) hacia una prohibición de orden religioso ('quam felix esses, si tu quoque luminis huius/ orbus' ait 'fieres, ne Bacchica sacra uideres! "Cuán feliz serías, dijo, si tú también estuvieras privado de esta luz y no vieras los ritos sagrados de Baco!" III, 517-518). Sémele se asemeja a sus allegados a partir de una muerte paradójica resultante de una transgresión de la esfera divina ( laeta malo nimiumque potens perituraque amantis/ obsequio Semele (...) "Alegre con su [futura] desgracia y excesivamente poderosa y a punto de morir por el obsequio de su amante" III, 292-293; corpus mortale tumultus / non tulit aetherios donisque iugalibus arsit "su cuerpo mortal no toleró la agitación divina y ardió con el regalo de su esposo" III, 308-309)

Ahora bien, la autodestrucción del linaje de Cadmo en las Metamorfosis adquiere un alcance simbólico a la luz de la guerra programática de los Espartos nacidos de los dientes de la serpiente abatida por el héroe fundador. Más aún, el motivo de la autodestrucción excede los límites del ciclo tebano. La historia tradicional de los soldados surgidos de la tierra permite vincular, pues, el tópico ovidiano de la transformación con la representación de la subversión de los lazos familiares y sociales en Roma. La paradoja de las arma fraterna mitológicas después del sacrilegio de Cadmo se instaura, así, como marco programático de los relatos siguientes:

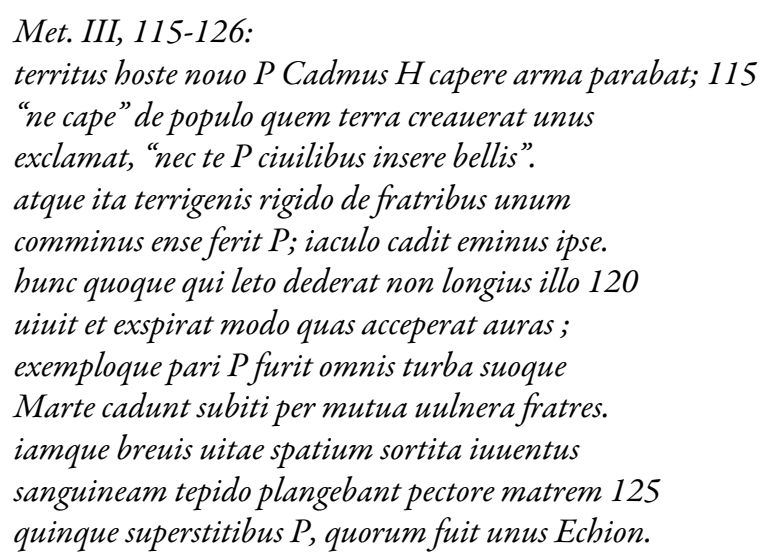

Aterrado por el nuevo enemigo, Cadmo se disponía a tomar las armas. "No las tomes", grita uno del pueblo que había engendrado la tierra; "y no te mezcles en una guerra civil". Y así hiere cuerpo a cuerpo con rígida espada a uno de sus hermanos nacidos de la tierra; él mismo cae por un dardo lanzado de lejos. También el que le había dado muerte a este no vive más que él y exhala el aliento que había recibido hace poco, y toda la muchedumbre se enfurece con el mismo ejemplo, y en su propia 
guerra con heridas recíprocas caen los repentinos hermanos. Y ya la juventud armada a la que le había tocado en suerte un breve espacio de vida golpeaba a su ensangrentada madre con su tibio pecho, siendo cinco los sobrevivientes, de los cuales, uno [fue] Equión.

El fundador de Tebas se ubica en el centro del verso que abre la escena (P Cadmus $\mathbf{H} 115)^{24}$ y queda enmarcado por dos motivos que anuncian en el texto la naturaleza inédita y sacrílega de su propia descendencia: el de un enemigo nuevo (hoste nouo 115) y el de una guerra civil (ciuilibus...bellis 117) ${ }^{25}$. El distanciamiento de Cadmo a partir de la advertencia del Esparto (115-116) introduce una ruptura respecto de las otras versiones del episodio mítico, donde el personaje es presentado como el instigador de la matanza fratricida ${ }^{26}$. Su inocencia en Ovidio establece no solo un contraste más marcado con las desgracias de sus descendientes, sino que habilita una lectura metapoética de esta especificidad ovidiana: el ego poético de las Metamorfosis se aleja también de las convenciones genéricas que subyacen en la escena a partir de ciertos contrastes con el discurso épico tradicional, según se desprende de la irónica alusión a un coraje guerrero demasiado efímero (breuis uitae spatium sortita iumentus 124) ${ }^{27}$. Asimismo, la inclusión de la ironía del narrador en el marco de un conflicto intestino altera, una vez más, la tradición del motivo épico a través de un entrecruzamiento paradójico de términos relativos a la guerra y a la familia, en la medida en que ambas esferas se excluían mutuamente en el imaginario cultural romano (fratribus 118; ense 119; iaculo 119; fratres 123; iuuentus ${ }^{28}$ 124; sanguineam... matrem 125) ${ }^{29}$. La confusión de ámbitos es explicitada también por la fluctuación entre la singularidad de los soldados (unus 116; unum 118; ipse 119; bunc...illo 120; unus 126) y su estatus de turba furens (122), que cuestiona y problematiza el tópico de la muerte en una batalla fratricida (Marte cadunt subiti per mutua uulnera fratres 123) ${ }^{30}$. Dicha fluctuación resulta aún más significativa a la luz de la progresión semántica que establece el pasaje: la 'unicidad' de los soldados es presentada, primero, respecto de la idea general de 'pueblo' ( de populo...unus 116), luego respecto de su parentesco (de fratribus unum 118) y, por último, respecto de un pronombre que aglutina al conjunto de los sobrevivientes de la matanza para introducir al primer descendiente del fundador (superstitibus, quorum...unus Echion 126).

Las metamorfosis del ciclo tebano se vinculan, entonces, con una autodestrucción que entrelaza el campo de acción bélica con los vínculos de parentesco. Si la pietas excesiva del padre de Europa y Cadmo lo impulsa hacia la decisión criminal de condenar a su hijo al exilio en caso de no encontrar a su hermana, el escrúpulo de pietas de este último tras haber consultado el oráculo de Apolo lo conduce también, como a su padre, a cometer un nefas ${ }^{31}$. Según mostraremos, la paradoja que enmarca la fundación mítica de Tebas en las Metamorfosis (pater facto pius et sceleratus eodem Met. III, 5 "padre piadoso y criminal con un mismo hecho") no solo abre el relato mítico en el poema, sino que se extiende fuera de él y, a la luz de una red intratextual ${ }^{32}$ , subraya los alcances reflexivos del recurso en la poética ovidiana.

\section{INSTANCIAS MÍTICAS DEL CONFLICTO FRATRICIDA: ENTRE CADMO Y MEDEA}

La idea de una guerra civil funciona como el eje de las paradojas que construyen el relato de la fundación de Tebas en el libro III de las Metamorfosis. En efecto, como señalamos anteriormente, la advertencia inicial que uno de los Espartos le hace a Cadmo ya dispuesto a tomar las armas frente al ejército nacido de la tierra (nec te ciuilibus insere bellis III, 117) constituye una novedad en la tradición poética de ese episodio mítico. La imagen es incluso retomada y desarrollada en el libro VII del carmen perpetuum en el contexto de la leyenda de Medea:

Met., VII, 121-153:

(...) galea tum sumit aena

uipereos dentes et aratos spargit in agros.

semina mollit humus ualido praetincta ueneno, 


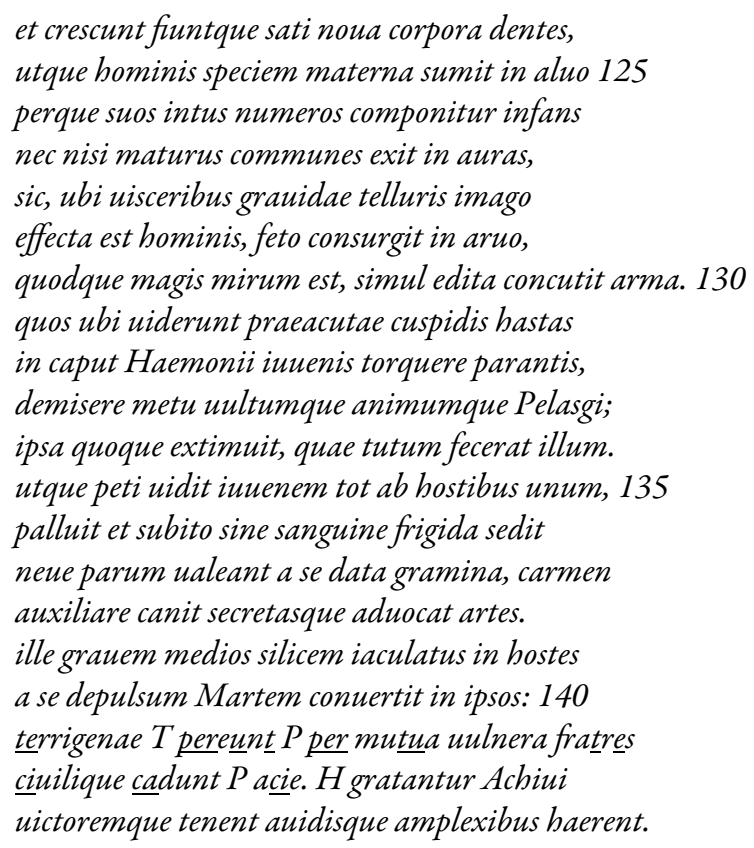

Toma entonces del broncíneo casco los dientes viperinos y los esparce en el campo arado. La tierra, empapada de antemano de poderoso veneno, ablanda las semillas y los dientes sembrados crecen y se convierten en nuevos cuerpos; y, del mismo modo que en el útero materno el niño adopta una figura de hombre y se forma dentro en cada uno de sus elementos y no sale al aire compartido a no ser cuando está maduro, así, cuando en las entrañas de la tierra grávida se ha completado la figura humana, se alza en el fecundo campo labrado, y, lo que es más admirable, en el mismo momento de nacer agita las armas. Cuando vieron que estos se disponían a disparar las lanzas de muy afilada punta contra la cabeza del joven hemonio, los pelagos dejaron caer por el miedo su cabeza y su ánimo. También sintió pánico la misma que lo había hecho invulnerable, y, cuando vio que el joven en solitario era atacado por tantos enemigos, palideció y de repente se sentó paralizada, sin sangre; y, para que no tengan poco efecto las hierbas por ella proporcionadas, entona un sortilegio de ayuda y recurre a sus artes secretas. Él, lanzando una pesada piedra en medio de los enemigos, arroja contra ellos mismos a Marte desviado de él; los hermanos nacidos de la tierra perecen por las heridas infligidas mutuamente y caen en una contienda civil. Los aquivos lo felicitan y toman al vencedor y lo estrechan con ansiosos abrazos.

La saga tebana y la saga argonáutica confluyen en la mención de los soldados surgidos de la tierra a partir de los dientes de la serpiente ${ }^{33}$ y en la consiguiente mención de su lucha en términos de un combate intestino 34 . El entrelazamiento de segmentos fónicos y la distribución de las cesuras en los versos que operan la asociación de episodios míticos (141-142) subraya la reciprocidad criminal propia de la matanza familiar, cuyo clímax es la clara designación del conflicto fratricida en el sintagma conclusivo (te rrigenae $T$ per e $\underline{u}$ $n \underline{t} P$ per mu tu a uuln er a fra tre s/ ci uilique ca dunt $P$ a ci e. H 141-142). Dos imágenes construyen la analogía entre las dos historias míticas: por un lado, la del movimiento paradójico del surgimiento de los soldados (consurgit 129) y su posterior caída (cadunt 142); por otro, la de la transformación de la tierra en un campo de batalla, según deja al descubierto la simetría de la configuración fono-semántica del final de los versos 129 y 130 ( con surgit in ar uo / con cutit ar ma). La auto-reflexividad del texto no solo se activa en el lector con las correspondencias entre ambas sagas en torno al motivo de una guerra civil, sino también con la insistencia en el acto de la visión (uiderunt 131; uidit 135) — uno de los ejes temáticos del libro III- y con la alusión a los noua corpora (124) de los soldados. En efecto, el canto mágico de Medea (137-138) parece evocar la operación intratextual misma que el poeta lleva a cabo implícitamente a través de la correspondencia léxica con el incipit de su carmen perpetuum (in nou fert animus mutatas dicere formas/ corpora I, 1-2). Si bien, en este caso, los 'cuerpos' aluden a los soldados nacidos de la tierra, lo cierto es que la descriptio siguiente de un enfrentamiento que 'mezcla' o diluye paradójicamente las nociones de 'enemigo' (ab hostibus 135; in hostes 139) y 'hermano' (pereunt...fratres 141) constituye una uariatio de la presentación inicial del caos en las Metamorfosis. Más precisamente, el episodio argonáutico del libro VII focaliza, a partir de la identificación 
con la saga tebana del libro III, una confusión de elementos o categorías que, desde su primera manifestación cósmica en el poema ${ }^{35}$, se carga de nuevos sentidos al asumir valencias sociales que entrecruzan el relato mítico de la creación del mundo con la representación romana de las guerras civiles ${ }^{36}$. Dicho mecanismo tan textual como ideológico se confirma a la luz de un pasaje de la Heroida XII (95-100): la misma figura de Medea permite retomar el tema de una guerra civil mítica que combina dos sagas con vistas a destacar la imbricación perturbadora entre la esfera familiar y la esfera bélica:

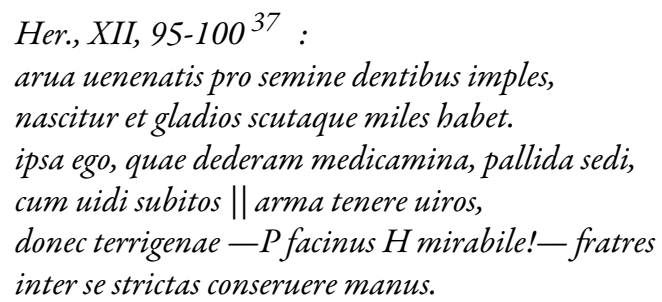

Llenas los campos con dientes envenenados en lugar de semillas; nace el soldado y empuña la espada y el escudo. Yo misma, que te había dado el antídoto, me senté, pálida, cuando vi que estos hombres imprevistos empuñaban las armas, hasta que, como hermanos nacidos de la tierra - ¡crimen admirable!- trabaron entre sí sus manos desnudas [listas para la lucha].

En primera persona y dentro del contexto elegíaco de la Heroida, Medea reproduce la voz del narrador del libro VII de las Metamorfosis para contar su propia historia. En este caso, el objeto de su mirada (uidi 98) es la escena fratricida que confunde o 'mezcla' el cuerpo de los soldados nacidos de la tierra (inter se strictas conseruere manus 95) ${ }^{38}$. Tal escena es designada como un crimen ( facinus 99), cuya intensidad subraya la posición central del término en el sintagma que explicita el carácter fratricida del enfrentamiento (terrigenae P facinus $H$... fratres 99). Más aún, el rasgo extraordinario (mirabile 99) de ese crimen se construye en el texto mediante una suerte de progresión léxico-semántica que evoca aquella que se señaló en el libro III (115-126): el término militar genérico (miles 96) ${ }^{39}$ hacia el final del segundo hemíepes del pentámetro deviene luego la designación de los soldados ya en relación con su rol social en el cierre del pentámetro siguiente (uiros 98) y culmina, paralelamente en la cláusula del hexámetro (fratres 99), con la focalización de la consanguinidad en el verso que hace referencia a la índole inaceptable del crimen intrafamiliar.

\section{Conclusiones}

La escritura ovidiana resulta un lugar privilegiado para el estudio del material mítico grecorromano desde una perspectiva que apunta a dilucidar los alcances de dicho material en sus respectivos contextos de enunciación y recepción. El enfoque "diferencial" 40 permite, pues, abordar las especificidades literarias y culturales de las actualizaciones míticas y, por ende, ahondar sus alcances intertextuales e intratextuales. Dentro de las tipologías que la cultura romana incorporó a su reelaboración de los temas mitológicos griegos, la saga tebana constituye una vía de acceso clave para el estudio de las variables estéticas y culturales que moviliza la (re)escritura de un relato mítico. Según hemos constatado, a través de la paradoja estilística el carmen perpetuum de Ovidio reescribe las matrices míticas de los ciclos tebano y argonáutico a los efectos de proponer una versión literaria de un motivo cultural persistente en Roma: el de las guerras civiles en tanto sacrilegio social inadmisible. Según ha sido demostrado por la crítica de corte antropológico ${ }^{41}$, dicho acontecimiento político afectó especialmente el sistema romano de creencias al superponer simbólicamente la esfera de la familia con la esfera de la guerra. La textualización del ciclo tebano (Met. III) y su conjunción con la saga argonáutica (Met. VII), incluso fuera del poema (Her. XII), da cuenta del valor ideológico que Ovidio detectó en esos episodios míticos y logró plasmar mediante una serie de módulos temáticos y narrativos que se convirtieron en un antecedente fundamental de la literatura posterior. Más exactamente, el peculiar uso ovidiano de la paradoja en tanto combinación de ideas contradictorias entre sí le permitió a este poeta de época augustal construir una matriz de lectura que trascendió el plano mítico en pos de la narración del motivo cultural de las fraternae neces, que perturbó a los romanos ya desde la época republicana. Si, por un 
lado, la paradoja habilitó en las Metamorfosis la narración singular de una herencia mítica de amplia difusión, lo cierto es que también permitió inscribir, implícitamente, una reflexión sobre el sinsentido y el sacrilegio de la lucha fratricida. Como ya señalamos al comienzo de nuestra propuesta, la literatura del período imperial, principalmente la tragedia de Séneca y la épica de Lucano, retomaría la impronta ovidiana en un nuevo contexto de producción y en el marco de una reformulación de los códigos genéricos tradicionales. En este sentido, las Metamorfosis se constituyen en un hipotexto clave dentro del sistema literario romano, cuyos alcances diacrónicos convendría, aún, profundizar.

\section{Notas}

1. Cf. La Penna, A., "Funzione e interpretazione del mito nella tragedia arcaica latina", en: Fra teatro, poesia e politica romana, Torino, Einaudi, 1979, 49-105; 127-141; Dangel, J., "Les dynasties maudites dans le théâtre latin de la République à l'Empire”, Ktema 12, 1987, 149-157; Gildenhard, I..- Revermann, M., (eds.), Beyond the Fifth Century: Interactions with Greek Tragedy from the Fourth Century BCE to the Middle Ages, Berlin - New York, De Gruyter, 2010, 153-185.

2. Cic., S. Rosc., XXIV, 66-68; Pis., XX, 47; Leg., I, 40.

3. Cf. Wheeler, S., "Lucan's Reception of Ovid's Metamorphoses", Arethusa 35, 2002, 361-380; Wheeler, S., "Into New Bodies: The Incipit of Ovid's Metamorphoses as Intertext in Imperial Latin Literature", MD 61, 2009, 147-160; Hinds, S., "Seneca’s Ovidian Loci", SIFC 9, 2011, 5-63

4. Esposito, P., "Su alcuni miti tragici in Lucano e nell'epica Flavia”, en: Thomas Baier (ed.) Götter und menschliche Willensfreiheit. Von Lucan bis Silius Italicus, München, Beck Vol.1, 99-126, 2012, 15.

5. Principalmente las Bacantes de Eurípides, que Ovidio retoma de manera explícita en el episodio de Penteo que cierra su libro III. Como bien observa Fabre-Serris, J., "Le cycle thébain des Métamorphoses: un exemple de mythographie genrée?”,EuGeStA 1,2011, 100: “la présence du texte grec, auquel Euripide a sans doute voulu répondre et qui est l'autre texte important de cette tradition, l'CEdipe-Roi de Sophocle, est, en revanche masquée, ce qui n'implique pas que son importance soit moindre dans l'ambitieux cycle conçu par Ovide comme une interprétation de la totalité de l'histoire de la dynastie thébaine".

6. Contrariamente a los abordajes que suponen un sentido universal inherente a los mitos, es decir, una mirada esencialista del material mítico, nuestro enfoque se inscribe en el llamado "comparativismo diferencial”, el cual apunta, más bien, a un análisis de las actualizaciones de dicho material en función de sus contextos de enunciación y re-enunciación. Al respecto, cf. Heidmann, U., "Différencier au lieu d'universaliser. Comparer les façons de (r)écrire des mythes", Interférences littéraires/Literaire interferenties 17, 2015, 15-34. Para un enfoque pragmático de los mitos grecorromanos, cf. Calame, C., Qu'est-ce que la mythologie grecque?, Gallimard, 2015, 89-107.

7. Dangel, J., "Devanciers grecs et romains de Sénèque le tragique”, en: Billerbeck, M.- Schmidt, E. (dir.), Sénèque le tragique, Vandœuvres - Genève, Fondation Hardt, 63-120.

8. Cf. Fabre-Serris, J., Mythe et poésie dans les Métamorphoses d'Ovide. Fonctions et significations de la mythologie dans la Rome augustéenne, Paris, Klincksieck, 1995, 215-238.

9. "ego tibi illa ipsa quae uix in gymnasiis et in otio Stoiciprobant ludens conieci in communes locos. Quae quia sunt admirabilia contraque opinionem omnium (ab ipsis etiam paradoxa appellantur), tentare uolui possentne proferri in lucem, id est in forum, et ita dici ut probarentur, an alia quaedam esset erudita alia popularis oratio: eoque scripsi libentius quod mibi ista paradoxa quae appellant maxime uidentur esse Socratica longeque uerissima".

10. Cuando Quintiliano enumera allí los distintos tipos de causas judiciales, incluye la causa "extraordinaria”, que los griegos llaman parádoxon (admirabile autem uocant quod est praeter opinionem hominum constitutum).

11. Como remarca Lausberg, H., Elementi di retorica, Bologna, il Mulino, 1969, 28-29: "Il paradosso intellettuale non si presenta solo come materia, ma anche come fenomeno di straniamento quindi come pensiero o come figura di pensiero o come figura di pensieri e di parole rintracciabile nella inuentio (fenomeni paradossali) (...) ne fanno parte l'ironia, l'enfasi, le litoti, l'iperbole, l'oxymoron, il chiasmo (...)".

12. Para una lectura metapoética de este aspecto, cf. Vial, H., La métamorphose dans les Métamorphoses d'Ovide. Étude sur l'art de la variation, Paris, Les Belles Lettres, 2010.

13. En su abordaje del género épico de época neroniana, Perutelli, A., La poesia epica latina. Dalle origini all'età dei Flavi, Roma, Carocci, 2000, 148, señala: "il paradosso, che in origine è uno dei tanti espedienti della retorica, viene assunto a principio costitutivo di un mondo in cui il male va di pari passo con l'irrazionalità. Tanto è il sovvertimento del mondo, che solo il paradosso può descriverlo e giustificarlo". 
14. Bernbeck, E.J., Beobachtungen zur Darstellungsart in Ovids Metamorphosen, Münich, Zetemata 43, 1967, 109-113; Diller, H., "Die dichterische Eigenart von Ovids Metamorphosen", en: von Albrecht, M.- Zinn, E. (eds.), Ovid, Darmstadt, 1968, 335; Lefèvre, E., "Die bedeutung des paradoxen in der römischen literatur", en: Geyer, P.Hagenbüchle, R. (hrsg.), Das Paradox. Eine Herausforderung des abendländischen Denkens, 1992, 218-224; Tissol, G., The Face of Nature. Wit, Narrative, and Cosmic Origins in Ovid's Metamorphoses, Princeton, Princeton University Press, 1997; Hardie, P., Paradox and the Marvellous in Augustan Literature and Culture, Oxford - New York, Oxford University Press, 2009, 162-181.

15. Sobre este tema, cf. Tola, E., La métamorphose poétique chez Ovide: Tristes et Pontiques. Le poème inépuisable, ParisLouvain- Dudley, Ma., 2004.

16. Gildenhard, I. - Zissos, A., "Somatic Economies: Tragic Bodies and Poetic Design in Ovid's Metamorphoses", en: Hardie, Ph., Barchiesi, A., Hinds, S., (eds.), Ovidian Transformations. Essays on the Metamorphoses and its Reception, Cambridge, Cambridge Philological Society, 1999.

17. Cf. Barchiesi, A., Ovidio. Metamorfosi. Volume I, Libri I-II. Trad. di Ludovica Koch, Milano, Fondazione Lorenzo Valla, 2007, 125: "La struttura del libro è molto più unitaria del consueto e ha pochi paralleli nel poema: tutti o quasi tutti i personaggi hanno una relazione con la famiglia di Cadmo e con i tempi più antichi della citta di Tebe in Beozia: una relazione genealogica, cronologica e territoriale (...); "La concatenazione delle storie su base geografica ristretta è una novità per quest'opera (...)".

18. Para el texto latino, seguimos la edición de Barchiesi, A., op.cit.

19. Sobre esta genealogía mítica, cf. Barchiesi, A., op. cit., 229.

20. Para una epifanía divina similar (Venus a Eneas), cf. Verg., A., II, $591-592$ (confessa deam qualisque uideri / caelicolis et quanta solet.).

21. Tiresias es hijo del Esparto Udeo, uno de los cinco fundadores sobrevivientes a la matanza fratricida.

22. La relación se produce sobre todo a través de los tres versos (III, 132-134) que operan la transición entre los relatos de Cadmo y Acteón, primer descendiente del fundador de Tebas en el ciclo ovidiano (Hos quoque iam inuenies; sed scilicet ultima Semper / Exspectanda dies homini est, dicique beatus / Ante obitum nemo supremaque funera debet ("pero ciertamente siempre ha de ser esperado el último día del hombre, y nadie debe ser llamado feliz antes de la muerte y de las últimas exequias"). Se trata indudablemente de un eco alusivo del cierre del Edipo de Sófocles: "No juzguemos feliz a nadie antes de que llegue al término de su vida sin haber sufrido ninguna desgracia" (1529-1530).Del mismo modo, la respuesta que le da Tiresias a la madre de Narciso (si se non nouerit Met. III, 348) es también una inversión paradójica del célebre precepto del oráculo de Apolo en Delfos, como lo confirman las palabras de Yocasta a Edipo en la misma tragedia de Sófocles (“desdichado, ojalá pudieras no saber quién eres” 1068). En cuanto a las huellas de Ovidio en la versión senecana de la tragedia de Edipo, cf. Vial, H. "Présence d'Ovide dans l' $O E$ dipe de Sénèque: formes et significations", $R E L$ 92, 2014, 163-195.

23. Al referirse al carácter macroestructural de la paradoja, Molinié, G., Dictionnaire de rhétorique, Paris, Librairie générale française, 1992, 235, señala que "l'oxymore est une figure de type microstructural, variété la plus corsée de la caractérisation non pertinente. Dans sa forme la plus générale, l’oxymore établit une relation de contradiction entre deux termes qui dépendent l'un de l'autre ou qui sont coordonnés entre eux; il sert de support éventuel à l'antithèse”. Según Lausberg, op. cit., 212: “Una variante particolare dell'antitesi di parole singole è l'oxymorum, che costituisce un paradosso intellettuale tra i membri antitetici”. Cf. también Adams, J. - Mayer, R., (eds.), Aspects of the Language of Latin Poetry, Oxford, Oxford University Press, 1999, 86, para un abordaje de dicho tropo en el discurso poético romano.

24. Las letras $\mathrm{P}$ y $\mathrm{H}$ indican, respectivamente, las cesuras pentemímera y heptemímera del hexámetro.

25. La paronomasia parcial entre los verbos ferit (119), referido a un término bélico (ense), y el verbo furit (122), asociado al comportamiento de los soldados (omnis turba), exhibe una arquitectura fónica que insiste en el carácter impío de la lucha entre estos hermanos nacidos de la tierra.

26. Según recuerda Fabre-Serris, J., “Le cycle thébain...”, 114: “Selon [Apollodore] (3, 4, 24), qui dit suivre Phérécyde, « Cadmos, lorsqu'il vit que des hommes tout armés poussaient de la terre, leur jeta des pierres et, chacun croyant être mitraillé par les autres, ils commencèrent à se battre ». Les différences avec Ovide sont parlantes: pas d'autodestruction spontanée et une expiation immédiate exigée du futur fondateur de Thèbes: « Cadmos, pour expier son meurtre, dut servir Arès pendant une année perpétuelle », autrement dit, huit ans, précise Apollodore (3, 4, 24)”. Ver también Wheeler, S., “Lucan's Reception...”, 376.

27. Se trata del motivo épico de la muerte de jóvenes héroes destinados a una breve existencia, ya plasmado por Homero y retomado luego, en Roma, por Virgilio (A., X, 508). Cf. Barchiesi, op. cit., 143, vv. 120-121.

28. OLD s.v. 1 b: "the men of military age (esp. those serving, the soldiery)".

29. Sobre los alcances literarios y culturales de esta idea en Roma, cf. Petrone, G., Metafora e tragedia. Immagini culturali e modelli tragici nel mondo romano, Palermo, 1996.

30. Cf. Met., VII, 141-142 (terrigenae pereunt per mutua uulnera fratres/ ciuilique cadunt acie).

31. Met., III, 710 (bic oculis illum cernentem sacra profanis ). 
32. Sobre esta dinámica literaria, cf. Sharrock, A. - Morales, H. (eds.), Intratextuality: Greek and Roman Textual Relations, Oxford, Oxford University Press, 2001.

33. Según Apolonio Rodio (III, 1176-1180), se trataría, en el caso de la saga argonáutica, de los dientes no sembrados del dragón de Cadmo.

34. Para una misma expresión, cf. Met. IX, 405 (pares in uolnere fratres); Tr. II, 319 (mutua uulnera fratrum). Séneca (Oed., 738-748) retoma y profundiza, a través del concepto de sacrilegio (ciuile nefas 748), la asociación de la historia de Tebas con el surgimiento de un nuevo pueblo (populique...recentis 744) y la del parentesco de esos soldados (Agmina...cognata 738) con la idea de monstruosidad (horret tantis aduena monstris 743 ).

35. Supra, p. 4

36. La analogía entre Roma y Tebas ha sido particularmente estudiada por Hardie, P., "Ovid's Theban History: the First anti-Aeneid?", $C Q 40,224-226 ; 230$.

37. Para el texto latino, seguimos la edición de Bornecque, H., Ovide. Héroïdes, Paris, Les Belles Lettres, 1999.

38. La insistencia en esta idea surge también de la sucesión de marcas léxicas y morfológicas que refieren a la reciprocidad (inter se), a la confusión de cuerpos (strictas...manus) y al crimen común (conseruere > con + sero OLD s.v.). La expresión conserere manus designa la acción de "to join in close combat" (OLD s.v. 4).

39. Cf. Ernout, A.- Meillet, A., Dictionnaire étymologique de la langue latine, Paris, Klincksieck, 19594, s.v.

40. Cf. Bruera, F., "Pour une nouvelle épistémologie des réécritures littéraires des mythes", Interférences littéraires/Literaire interferenties 17, 2015, 7-12.

41. Cf. Petrone, G., Metafora e tragedia...; Guastella, G., "La rete del sangue: simbologia delle relazioni e modelli dell'identità nella cultura romana”, MD 15, 1985, 49-123; Lennon, J., Pollution and Religion in Ancient Rome, Cambridge, 2014. 